\title{
A TRIBUTE TO RENEE KRA: RADIOCARBON MANAGING EDITOR FOR 30 YEARS
}

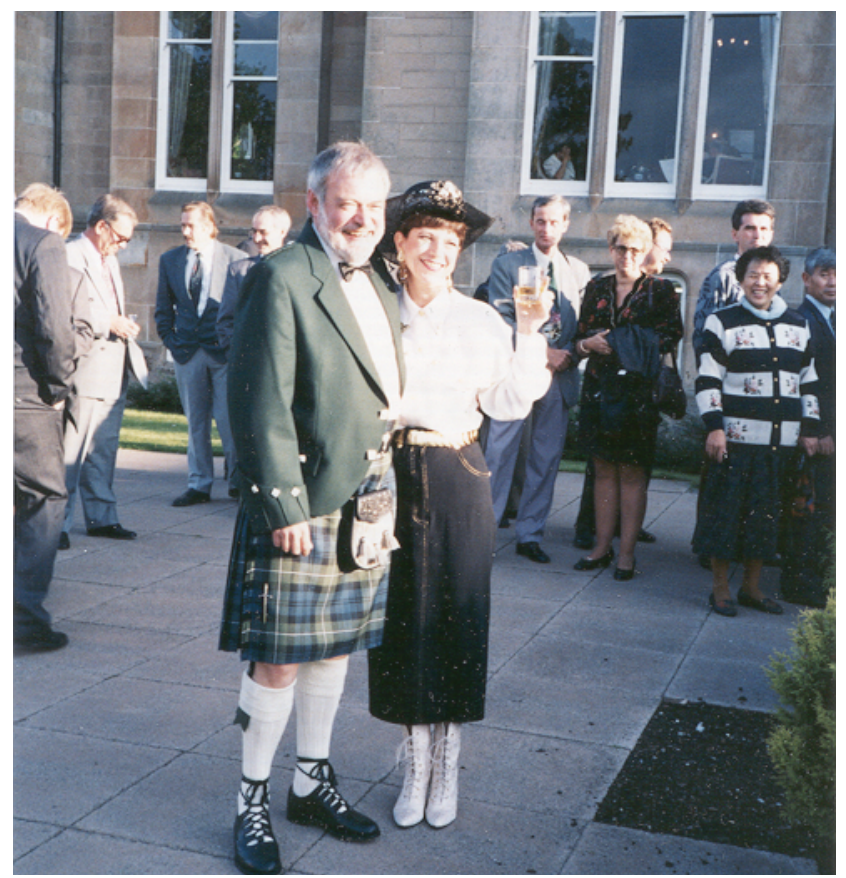

Renee and Doug Harkness (the cowgirl and the kiltie) sample Scotch whiskey near Loch Lomond, Scotland during a mixer at the 1994 LSC Conference.

An author begs Renee for a later submission deadline at the June $1988{ }^{14} \mathrm{C}$ Conference in Dubrovnik, Yugoslavia.

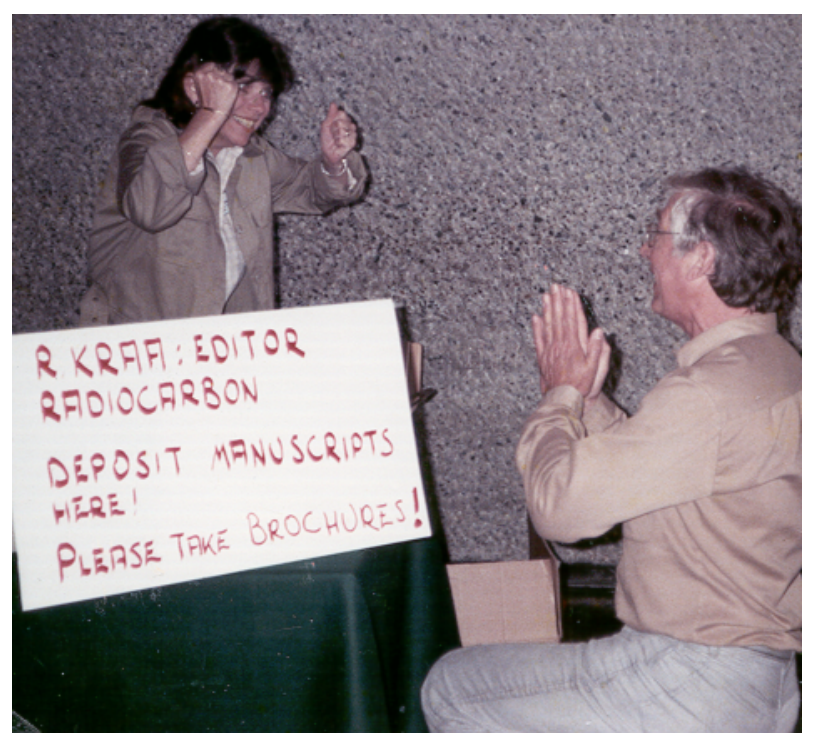



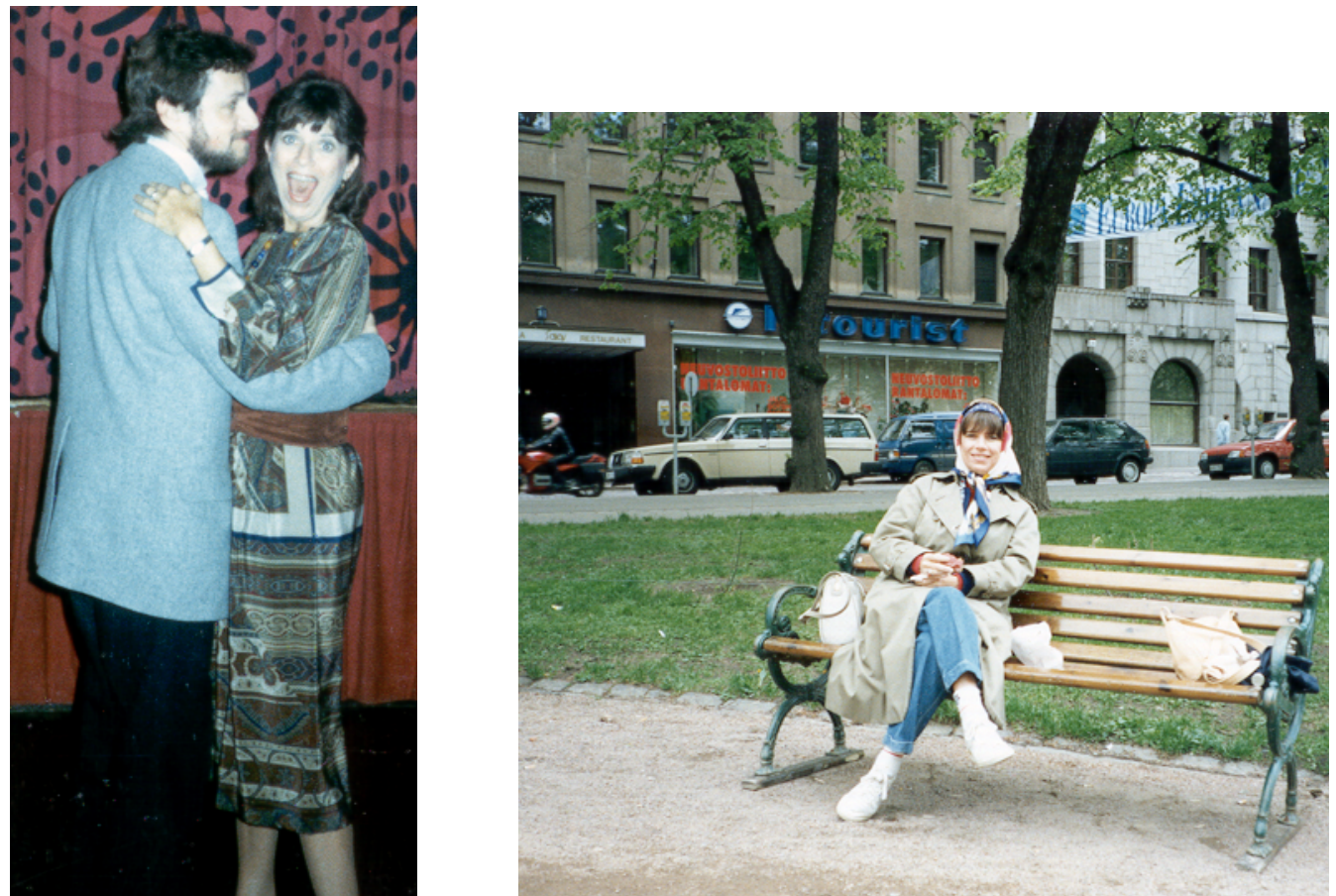

Left: Renee is caught by surprise while dancing with Gordon Cook during the Second International Symposium on ${ }^{14} \mathrm{C}$ and Archaeology in Groningen, the Netherlands, in September 1987. Right: Renee tours Helsinki in May 1990.
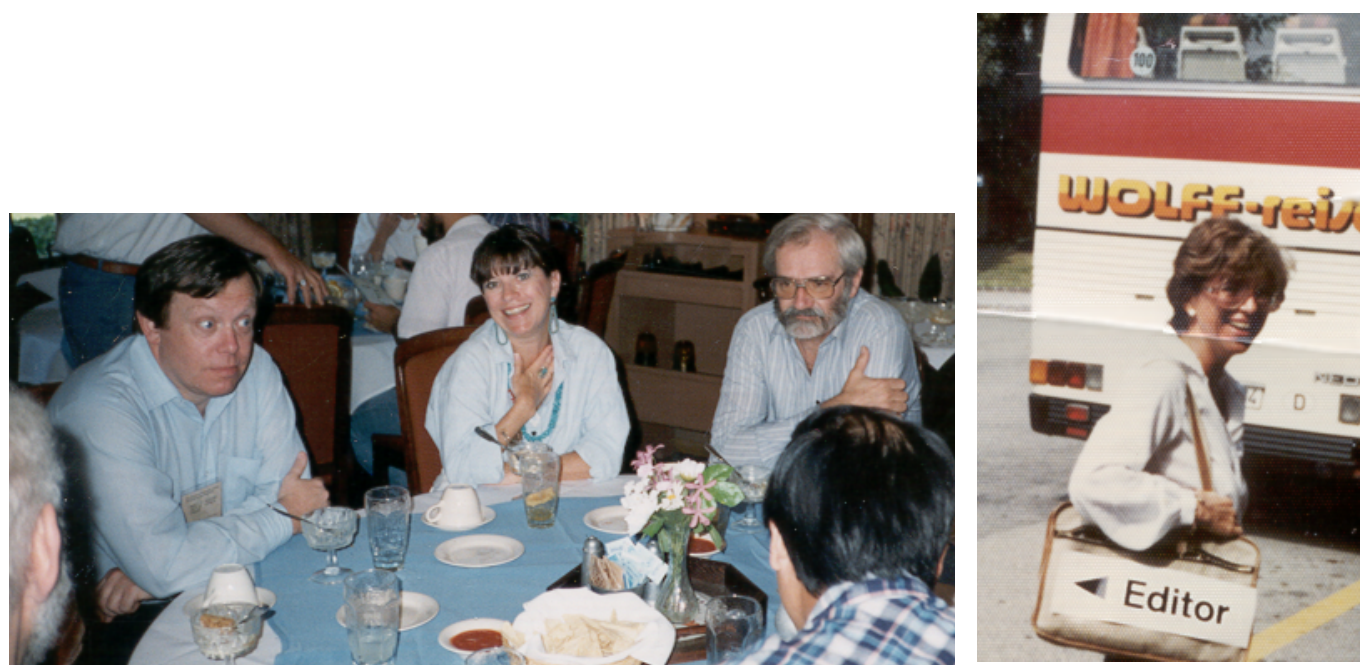

Left: Renee is joined by friends in June 1990 at the University of California Lake Arrowhead Conference, the proceedings of which were published jointly by Radiocarbon and Springer-Verlag in Radiocarbon After Four Decades. Former Editor Austin Long is seated to her left. Right: A clearly labeled Renee prepares to board a tour bus during the August $1979{ }^{14} \mathrm{C}$ Conference in Bern and Heidelberg, Germany (apologies for the photo quality). 